\title{
Ciências sociais em saúde: perspectivas e desafios para a saúde coletiva
}

\author{
Social sciences in health: perspectives and challenges for collective \\ health
}

Patricia Tavares Ribeiro', Leonardo Castro ${ }^{\mathbf{1}}$

DOI: 10.1590/0103-11042019S713

\begin{abstract}
RESUMO Desde a institucionalização da saúde coletiva, dos movimentos pela redemocratização e pela Reforma Sanitária até os dias atuais, transformações importantes ocorreram na sociedade brasileira e no mundo. Nas últimas décadas, as ciências sociais vêm buscando acompanhar essas transformações e desenvolver a reflexão sobre seus impactos. No campo da saúde coletiva brasileira, as chamadas 'ciências sociais e humanas em saúde’ refletem essa dinâmica, introduzindo novos objetos de estudo e abordagens, assimilando também inovações oriundas da teoria social. O presente ensaio propõe uma releitura da trajetória das 'ciências sociais em saúde' no Brasil e as mudanças verificadas em sua produção desde os estudos pioneiros do campo até os dias atuais, no bojo do processo da institucionalização da saúde coletiva como área de conhecimento especializada. Busca-se identificar desafios e perspectivas para o desenvolvimento da subárea considerando as transformações que afetam a problemática sanitária nas sociedades contemporâneas. Reconhecendo a contribuição das ciências sociais em saúde para a compreensão dos processos saúde-doença e das políticas de saúde, argumenta-se que as transformações sociais recentes requerem um investimento intelectual renovado, capaz de contemplar as novas dinâmicas sócio-políticas e a produção social dos riscos, bem como trazer aportes mais adequados à formulação de respostas governamentais no setor saúde.
\end{abstract}

PALAVRAS-CHAVE Ciências sociais. Saúde pública. Determinantes Sociais da Saúde.

ABSTRACT From the institutionalization of collective health and the movements for redemocratization and Sanitary Reform to the present day, important changes have occurred in Brazilian society and in the world. In the last decades, the social sciences have been seeking to track these transformations and reflect on their impacts. In the Brazilian Collective Health field, the so-called 'social and human health sciences' reflect this dynamic, introducing new objects of study and approaches, as well as assimilating innovations from social theory. This essay proposes a rereading of the trajectory of the 'social sciences in health' in Brazil and the changes in its production since the pioneer studies of the field to the present day, along the process of the institutionalization process of collective health as a knowledge area, seeking to identify challenges and perspectives for the development of the area, considering the transformations that affect health in contemporary societies. Acknowledging the contribution of the social sciences in health to the understanding of health-disease processes and health policies, we argue that recent social transformations require a renewed intellectual investment to address the new socio-political dynamics and social production of risks, as well as

1 Fundação Oswaldo Cruz (Fiocruz), Escola Nacional de Saúde Pública Sergio Arouca (Ensp) - Rio de Janeiro (RJ), Brasil. patriciatr@ensp.fiocruz.br bringing more appropriate inputs to governmental responses in health sector.

KEYWORD Social sciences. Public health. Social Determinants of Health. 


\section{Introdução}

No final da década de 1970, o conceito de 'saúde coletiva' emerge como inovação na produção de conhecimentos da saúde pública brasileira, ao articular contribuições de diferentes campos disciplinares, entre eles, as ciências sociais. Tal inovação inscrevia-se numa tendência presente na 'medicina social' latino-americana, de abordar os fenômenos saúde-doença em seus aspectos sociais, especialmente a partir da obra e do trabalho de articulação realizado por Juan César García, à frente do Departamento de Pesquisa da Organização Pan-Americana da Saúde (Opas) desde fins da década de 1960. Refletia, igualmente, trabalhos referenciais de autores brasileiros nos anos 1970 que abordavam as relações entre medicina, saúde e sociedade ${ }^{1}$.

Passadas quatro décadas, a saúde coletiva se tornou 'área básica' vinculada à 'grande área' das ciências da saúde na Tabela de Áreas de Conhecimento ${ }^{2}$ da Coordenação de Aperfeiçoamento de Pessoal de Nível Superior (Capes), do Ministério da Educação. Os representantes da área, junto à Capes, identificam-na atualmente como 'campo científico de natureza interdisciplinar', cujas disciplinas básicas são a epidemiologia, as ciências sociais e humanas em saúde e a política, planejamento e gestão de sistemas e serviços de saúde ${ }^{3(9)}$

O contexto de emergência desse campo e o contexto atual de sua produção são muito distintos. No final da década de 1970, a então emergente saúde coletiva designava um conjunto de saberes e práticas em desenvolvimento no campo da medicina, referente a uma abordagem ampliada do processo saúde-doença, incluindo aspectos políticos e econômicos, fortemente apoiado pelo diálogo da epidemiologia com as ciências sociais e articulado aos movimentos por mudanças na política de saúde e pela redemocratização do País. Ao final da segunda década do século XXI, o 'campo' da saúde coletiva, embora preserve importantes características da fase inicial, orientando estudos e pesquisa para a consolidação de um sistema público e universal de saúde, constitui-se como uma área de conhecimento especializada e institucionalizada, agregando numerosos programas de pós-graduação (e, recentemente, também cursos de graduação) integrados a um complexo sistema nacional de ciência e tecnologia, com regras estritas de credenciamento e avaliação.

Entre um momento histórico e outro, a 'natureza interdisciplinar' permanece como divisa do 'campo', mas mudanças ocorreram, reposicionando a contribuição das ciências sociais. Em levantamento relativamente recente da composição dos programas de pós-graduação acadêmicos stricto sensu da área, Iriart e colaboradores ${ }^{4}$ mostraram que, entre os 748 docentes do quadro permanente da pós-graduação em saúde coletiva, no triênio 2010-2012, 49,8\% deles podem ser classificados como epidemiologistas. Os autores afirmam que a maior incorporação aos programas de docentes da subárea epidemiologia - e menor de ciências sociais e humanas - assegura maior probabilidade de obtenção de melhores desempenhos no sistema de avaliação.

Em artigo de 2012, Costa $^{5}$ já assinalava o impacto da difusão do modelo biomédico de circulação da produção científica sobre a avaliação da produção das ciências sociais e humanas em saúde e alertava para o 'declínio da interdisciplinaridade na saúde coletiva'.

As vicissitudes da institucionalização explicam em parte essas mudanças: progressivamente, a saúde coletiva incorporou-se à 'ciência normal', conforme o termo empregado por Thomas Kuhn', e passou a se orientar por padrões internacionais que não contemplam necessariamente a pretensão de interdisciplinaridade que caracterizou originalmente o campo. Nesse contexto e sob o impacto de um sistema de incentivos que privilegia a produtividade com base em parâmetros bibliométricos, a ascendência da epidemiologia e o declínio da participação das ciências sociais na pós-graduação na área tornaram-se um resultado previsível.

Outra ordem de problemas está relacionada às especificidades e limites do conhecimento sobre o mundo social. O tipo de generalizações produzidas pelas ciências sociais apresenta 
diferenças fundamentais em comparação com as ciências naturais. Como observou Giddens ${ }^{7}$, enquanto as ciências naturais implicam uma relação do tipo sujeito-objeto, em que é possível identificar padrões e desenvolver generalizações a partir da observação, a pesquisa em ciências sociais envolve relações complexas entre sujeitos e é necessariamente interpretativa, pois, para descrever adequadamente o que um determinado agente social está fazendo, é necessário conhecer (ou supor) os meios e instrumentos simbólicos e cognitivos que orientam sua ação no desempenho da atividade.

Sendo o conhecimento sobre o mundo social, ele mesmo, parte do mundo social que pretende compreender ou explicar, constrói-se a partir de uma matriz simbólica, que precisa ser explicitada, e exige o saber reflexivo sobre a própria ordem social. Assim, o desenvolvimento de um conhecimento social objetivo é precedido de pré-condições e supõe procedimentos mais abrangentes em termos das dimensões que precisa contemplar.

O problema da interdisciplinaridade, porém, não se reduz à maior ou menor participação das matrizes disciplinares na pós-graduação da área. Recentemente, importantes reflexões sobre essa questão e, em particular, sobre o papel das ciências sociais na saúde coletiva têm surgido, inclusive de autores que desempenharam papel pioneiro no 'campo', como Madel Luz ${ }^{8,9}$, Maria Andrea Loyola ${ }^{10,11}$ e Cecília Minayo ${ }^{12,13}$, que são alguns exemplos significativos.

Não é intuito do presente ensaio retomar as reflexões sobre interdisciplinaridade ou questões relativas aos padrões de produtividade e possíveis impactos do modelo de avaliação, embora se reconheça a relevância desses debates. Um aspecto importante, por exemplo, que não tem recebido a devida atenção - a separação operada pela saúde coletiva entre o estudo das 'políticas' e das 'ciências sociais e humanas' -, é outro tópico que precisaria ser melhor analisado.

Ao problematizar o papel e o lugar das ciências sociais e humanas na saúde coletiva na contemporaneidade, pretende-se explorar as mudanças no contexto político e social que acompanharam a institucionalização da saúde coletiva como área de conhecimento, os impactos sobre a produção científica e os desafios para as análises do campo.

Desde os inícios da saúde coletiva, na conjuntura dos movimentos pela redemocratização e pela Reforma Sanitária, passando pela Assembleia Nacional Constituinte e pelo longo período de consolidação do Sistema Único de Saúde (SUS), até os dias atuais, em que as políticas sociais e o sistema de proteção social engendrados pela Constituição de 1988 encontram-se sob risco, transformações importantes ocorreram na sociedade brasileira e no mundo.

As ciências sociais, no Brasil e no mundo, vêm buscando nas últimas décadas acompanhar essas transformações e desenvolver a reflexão sobre seus impactos. No microcosmo do 'campo da saúde coletiva', as chamadas ciências sociais e humanas em saúde refletem essa dinâmica, com algumas peculiaridades. De um lado, buscam problematizar o mundo social e acompanhar suas transformações, traduzidas em novos objetos de estudo e novas abordagens; de outro, buscam, também, assimilar as inovações e mudanças no próprio campo da teoria social.

Neste ensaio, serão abordados alguns desafios postos para a saúde coletiva na contemporaneidade, a partir da trajetória institucional das ciências sociais em saúde na América Latina e no Brasil, vis-à-vis o surgimento de novas e plurais abordagens e temáticas que problematizam as relações entre saúde e sociedade.

Alguns estudos sobre a produção específica das 'ciências sociais e humanas em saúde' nas últimas décadas - entre eles, os realizados por Canesqui14,15 e Nunes ${ }^{16}$ - serão mobilizados para proporcionar uma perspectiva 'panorâmica' sobre a evolução e a institucionalização dessa produção no período recente. A partir desse percurso, buscar-se-á analisar os esforços da subárea na tarefa da incorporação de temáticas e abordagens que se mostrem capazes de fazer frente aos desafios postos pelo mundo social e suas transformações. Estudos 
recentemente publicados por Ianni17 informaram substancialmente essa perspectiva e serão discutidos na parte final do artigo, juntamente com outros autores que buscaram aproximar a reflexão das ciências sociais das transformações e dos desafios contemporâneos.

\section{O conhecimento social na interface com a saúde - origens institucionais}

Segundo Collins ${ }^{\mathbf{1 8}}$, o desenvolvimento de um conhecimento social 'objetivo' possui pré-condições que só recentemente puderam ser satisfeitas: a emergência de um grupo diferenciado de 'especialistas' e, com isso, de uma 'comunidade intelectual' na qual a busca do conhecimento torna-se um valor em si mesmo; e a 'racionalização' da sociedade (no sentido que Max Weber empresta ao termo), com o surgimento de atitudes pragmáticas com relação às trocas sociais, no âmbito do comércio ou da administração.

Foi o surgimento das universidades no Ocidente medieval que viabilizou a constituição de uma tal comunidade intelectual, com a criação de um ambiente institucional estável para o seu desenvolvimento, ao obter da Igreja e dos governantes prerrogativas que garantiam sua autonomia relativa. Mas foi a segunda pré-condição, a 'racionalização' das práticas de governo e no âmbito dos negócios privados, que deu ensejo à grande tradição de pensamento político da Europa ocidental, e, posteriormente, o movimento do Iluminismo, que inauguram a teoria social moderna ${ }^{18}$.

Somente no século XX a atual divisão disciplinar 'universitária' da investigação sobre o mundo social se consolida e institucionaliza. Cria-se, assim, um campo disciplinar específico e plural, que institucionaliza e legitima a pesquisa científica sobre o mundo social no contexto do saber universitário.

Segundo Rosen ${ }^{19}$, a emergência de uma 'medicina social' na Europa do século XVIII está associada ao surgimento de burocracias governamentais profissionalizadas e políticas orientadas para o aumento da riqueza e do poder dos Estados, isto é, ao contexto de racionalização administrativa e econômica apontado por Collins. Foucault ${ }^{20}$, em argumento semelhante, assinala o 'nascimento da medicina social' na Europa sob a forma de um conjunto de dispositivos de intervenção sobre o 'corpo' social visando ao aumento do poder do Estado, por meio do controle de epidemias, do ordenamento do espaço urbano, do controle sobre a reprodução da força de trabalho e da vigilância sobre segmentos marginais da população.

Entretanto, será a partir de sua institucionalização e incorporação à universidade que as ciências sociais tomarão a saúde e a medicina propriamente como objeto de estudo. $\mathrm{Na}$ segunda metade do século XX, em especial, nos Estados Unidos, a consolidação da sociologia como disciplina universitária abriu campo para a investigação sistemática tanto da prática médica como dos fenômenos relacionados ao processo saúde/doença. Sob o influxo do estrutural-funcionalismo, associado aos nomes de Parsons e Merton, inicia-se um processo de colaboração entre profissionais de saúde, principalmente médicos e cientistas sociais, em torno de uma agenda de reformas no campo da assistência e da educação médicas ${ }^{21}$.

No pós-guerra, a expansão de um modelo de assistência médica socializada sob controle estatal na zona de influência da antiga União Soviética e, por outro lado, o surgimento de sistemas nacionais públicos de saúde na Europa ocidental colocaram em questão o modelo liberal de medicina dominante nos Estados Unidos. Surge, assim, naquele país, o movimento da medicina preventiva e comunitária, que terá forte influência sobre o contexto brasileiro e latino-americano, a partir dos anos 1950, por meio de iniciativas de cooperação técnica, visando à reforma do ensino médico e a tornar a prática médica mais permeável às demandas sociais, sem romper, porém, com o modelo liberal1.

Nesse período, a difusão das ciências sociais no campo médico se deu sob o modelo das ciências da conduta, marcado pelos enfoques 
culturalista e comportamental da sociologia, antropologia e psicologia social norte-americanas, visando a corrigir distorções de uma medicina excessivamente individualizada.

Tais esforços descentravam o enfoque estritamente biológico do processo saúde-doença, incorporando à análise a complexidade biopsicossocial' do indivíduo, relações familiares e aspectos socioculturais. Tiveram papel central nessas inciativas algumas grandes fundações empresariais privadas norte-americanas - Rockfeller, Kellog, Milbank, Ford -, que atuaram como financiadoras de projetos de cooperação, assim como a Opas, e incluíram entre suas principais estratégias o recrutamento de docentes para realizar treinamento em universidades norte-americanas, para difundir o enfoque da medicina preventiva nos países da América Latina'.

Canesqui ${ }^{14}$ observa que a introdução das ciências sociais no campo da saúde no Brasil foi parte do processo de reformulação do ensino médico mediante a inclusão do ensino da medicina preventiva e integral nas faculdades de medicina, como suporte acadêmico às proposições de reorganização da prática clínica.

A abordagem da Opas sofreria uma importante inflexão na segunda metade dos anos 1960, sob a liderança de Juan César García, médico e cientista social nascido na Argentina, que passa a integrar a organização em 1966. Até 1983, quando de sua morte prematura, García estimulou a formação de núcleos de medicina social em diversos países e instituições latino-americanas, além de promover diversos seminários e reuniões sobre ciências sociais e saúde, com destaque para os encontros realizados em Cuenca, no Equador, em 1972 e 198322. Sua influência refletiu-se, sobretudo, na consolidação de uma abordagem mais crítica às relações entre saúde e sociedade, da produção social do processo de adoecimento e da organização dos serviços de saúde, trazendo novos referenciais para o campo da medicina social.

Tão importante quanto suas contribuições teóricas foi seu trabalho de articulação, promovendo o intercâmbio entre docentes e pesquisadores de vários países - e entre docentes e instituições em um mesmo país, como foi o caso do Brasil - e, também, junto às fundações norte-americanas que financiaram projetos de implantação de centros de ensino e pesquisa na região na década de $1970^{1}$.

Nesse contexto, desenvolve-se uma nova abordagem da relação entre medicina e sociedade, na qual o 'social' é apreendido não como uma variável adicional, mas como o terreno sobre o qual se constrói o 'processo saúde-doença'16,22,23. Nessa abordagem, os conhecimentos gerados sobre a saúde e a medicina buscam uma perspectiva multidisciplinar, colocando em diálogo diferentes perspectivas teóricas e metodológicas para compreender a relação entre estrutura social e processos sociais, visando a superar concepções estáticas das realidades e práticas sanitárias, em favor de uma compreensão dinâmica das relações entre saúde e outros aspectos da vida social' ${ }^{16}$.

Sobretudo os estudos vinculados à epidemiologia social buscavam compatibilizar dois modelos de causalidade na compreensão da 'determinação social da doença': o natural e o histórico. A perspectiva de relacionar/ contextualizar o processo saúde-doença na sociedade orientou investigações sobre as condições sob as quais se produzem, desenvolvem e reproduzem os fenômenos relacionados à saúde, enfocando aspectos sociais de diferentes doenças e agravos e, destacadamente, a relação entre trabalho e adoecimento. Outra vertente de estudos se dedicou a analisar as articulações entre medicina e outras práticas sociais em seus contextos históricos, tomando como objeto a medicina estatal, a assistência à saúde, profissões de saúde e mercado de trabalho, bem como atitudes e condutas da população frente aos serviços de saúde ${ }^{16}$.

Para García, escrevendo no início da década de 1980, o elemento unificador das abordagens que surgiam sob diferentes denominações na América Latina era "o estudo dos determinantes sociais da doença e dos serviços de saúde"23(21). Everardo Nunes ${ }^{16}$, analisando a produção latino-americana sobre 'ciências sociais aplicadas à saúde’ em um período de 
três décadas (1950-1979), a partir de uma base composta por 1.663 itens bibliográficos, corrobora a avaliação de García, especialmente para a última década pesquisada, na qual os estudos sobre 'processo saúde-doença' e 'serviços de saúde' formam quase $60 \%$ dos títulos analisados. Especificamente quanto ao 'processo saúde-doença', chama a atenção o grande número de trabalhos sobre aspectos sociais da nutrição e da saúde mental, que, juntos, formam quase metade dos itens listados, como também os estudos sobre 'determinantes sociais da morbimortalidade' e 'saúde-doença e sociedade', que abarcam $30 \%$ das publicações na categoria. $\mathrm{O}$ autor registra o grande aumento de estudos sobre aspectos sociais do processo saúde-doença na década de 1970, com alguns países apresentando "interessantes propostas dentro das correntes teóricas do materialismo histórico"16(50).Com relação aos estudos sobre 'determinantes sociais da morbimortalidade', Nunes reconhece a contribuição dos estudos que cruzaram morbimortalidade e variáveis sociais, revelando a situação precária de determinados segmentos populacionais e as diferenças entre grupos sociais, observando, porém, que estes colocam-se "dentro do marco de análise desenvolvido pela epidemiologia tradicional"16(52).

Assim, institucionalizou-se uma produção de conhecimentos específica na medicina social latino-americana, denominada 'ciências sociais em saúde’.

\section{Ciências sociais e saúde coletiva - a trajetória brasileira}

Ao contrário do que ocorreu nos Estados Unidos, em que os estudos sociais sobre saúde e medicina foram organizados como especialidades no âmbito das diferentes ciências sociais, que se desenvolveram à margem da grande área da public health, mais orientada para a investigação epidemiológica, no
Brasil, buscou-se constituir um novo campo distintamente interdisciplinar, cuja denominação - saúde coletiva - resulta da intenção consciente de distinguir-se da 'saúde pública' convencional'.

Inicialmente, a aproximação entre ciências sociais e saúde ganha espaço no campo médico e das escolas médicas, especialmente no âmbito de atividades docente-assistenciais da medicina preventiva e da medicina comunitária, em contexto de endurecimento do regime político pós 1968, que afetou o ensino superior e a saúde pública, em particular.

A partir da distensão política iniciada no Governo Geisel, demandas governamentais orientadas por perspectivas de racionalização do gasto setorial deram ensejo a iniciativas reformistas no campo do ensino e da assistência médica, inclusive com a participação de quadros com posicionamento crítico ao regime. É possível que o prestígio social ligado à profissão médica e a chancela das fundações filantrópicas norte-americanas e da Opas tenham contribuído para a participação de setores críticos ao regime nessas iniciativas e para uma atitude mais permeável ao novo conhecimento, gerado a partir de atividades docente-assistenciais. Por outro lado, havia demanda, decorrente da unificação previdenciária promovida pelo governo nos anos 1960, por iniciativas que apontassem medidas racionalizadoras para a gestão e a assistência médicas.

Neste contexto, surge um movimento de crítica aos paradigmas da medicina preventiva e comunitária, do exercício profissional da medicina e das práticas e da organização dos serviços de saúde prevalecentes. Esse movimento emerge nos núcleos e departamentos de medicina preventiva, comunitária e saúde pública, bem como em serviços de 'medicina integral' e cursos 'experimentais', em universidades e instituições públicas brasileiras, particularmente no Rio de Janeiro, em São Paulo e na Bahia 1 . As teses de doutorado ${ }^{24}$ e livre docência ${ }^{25}$ apresentadas por Cecília Donnangelo ao Departamento de Medicina Preventiva da Universidade de São Paulo e 
a tese de doutorado de Sergio Arouca ${ }^{26}$, defendida junto ao Departamento de Medicina Preventiva da Universidade Estadual de Campinas, foram as principais expressões desse movimento crítico no plano teórico. As pesquisas de Donnangelo e Arouca buscavam compreender a inserção do trabalho médico na sociedade e o papel da medicina no processo produtivo, mas, também, na reprodução das estruturas sociais existentes.

A pesquisa acadêmica em ciências sociais, por sua vez, foi bastante afetada pelo contexto político, com a desestruturação de polos de desenvolvimento da sociologia no País, embora tenha sido possível, em alguns casos, preservar padrões de produção intelectual elevados a partir de posições institucionais no exterior e extrauniversitárias. Como na saúde, fundações filantrópicas americanas, particularmente a Fundação Ford, desempenharam papel fundamental na sustentação da pesquisa social no período ${ }^{27}$.

Na segunda metade da década de 1970, a pesquisa em ciências sociais será reorganizada, ainda sob o regime militar, mas já em processo de distensão, por meio de uma política nacional de desenvolvimento da pós-graduação ${ }^{28}$, em um processo que foi igualmente decisivo para o campo, então em vias de constituição, da 'saúde coletiva'29. Quatro fatores concorreram para o desenvolvimento da 'saúde coletiva' brasileira no período: a) surgimento de novas demandas do próprio Estado, no contexto de reformulação estatal da assistência médica e do ensino médico; b) articulação latino-americana, protagonizada pela Opas de Juan César García, pela consolidação de um novo espaço de reflexão e intervenção, através da formação de recursos humanos e implementação de núcleos de medicina preventiva e social; c) grupos de profissionais de saúde insatisfeitos com o padrão de intervenção da medicina e da ação estatal na saúde; e d) conjuntura de distensão política e valorização do planejamento e da ciência e tecnologia como suporte às estratégias de desenvolvimento social ${ }^{29}$.

No período Geisel, foram implementados importantes programas estatais de fomento à produção científica e tecnológica, que destinaram recursos para investimento em infraestrutura, pesquisa e formação de recursos humanos. Razões associadas à necessidade de modernização da economia, visando à correção de distorções e desequilíbrios da matriz produtiva, mas, também, distribuição de renda, expansão do mercado de consumo de massa e redução da pobreza, deram ensejo a diversos programas de investimento em desenvolvimento social capitaneados pela Secretaria de Planejamento do governo federal, então diretamente vinculada à Presidência da República ${ }^{29}$.

O II Plano Nacional de Desenvolvimento e o II Plano Básico de Desenvolvimento Científico e Tecnológico afirmavam a necessidade da presença ativa do Estado na economia, por meio do fortalecimento do planejamento governamental e da articulação de uma política social e do fomento à incorporação de conhecimento técnico, visando ao desenvolvimento econômico e à competitividade internacional ${ }^{29}$.

O Programa de Desenvolvimento Social (Prosoci), criado em 1975, no âmbito da Financiadora de Estudos e Projetos, à época vinculada ao Conselho Nacional de Pesquisa Científica, deu impulso decisivo ao desenvolvimento das 'ciências sociais em saúde' e, com isso, à institucionalização da 'saúde coletiva' como campo de produção científica. Entre as iniciativas apoiadas pela Finep, foram especialmente importantes o Programa de Estudos Socioeconômicos em Saúde (Peses) e o Programa de Estudos e Pesquisas Populacionais e Epidemiológicas (Peppe), desenvolvidos na Escola Nacional de Saúde Pública, e o Programa de Apoio ao Mestrado, do Instituto de Medicina Social da Universidade do Estado do Rio de Janeiro. A importância desses programas estende-se ao trabalho de articulação de uma rede de instituições acadêmicas que desenvolviam atividades docentes-assistenciais a títulos diversos em núcleos e departamentos de saúde pública, medicina preventiva, medicina comunitária e medicina social no País ${ }^{\mathbf{1} 29}$. A rede assim formada foi instrumental para a criação, em 
setembro de 1979, da Associação Brasileira de Pós-Graduação em Saúde Coletiva (Abrasco).

A identidade da produção científica da saúde coletiva no Brasil se constitui a partir do esforço de construção de um novo marco teórico para a compreensão do processo saúde-doença e da realidade sanitária, em seus determinantes sociais. Tais esforços buscavam elucidar os processos geradores das condições de saúde/doença, a organização dos recursos assistenciais, bem como a dinâmica do desenvolvimento tecnológico no setor, por meio de estudos com forte embasamento na teoria social que apontavam para o desenvolvimento de uma 'teoria social da medicina' ou de uma 'teoria crítica da saúde', incluindo a análise das práticas assistenciais e da intervenção estatal no campo sanitário.

A incorporação das ciências sociais à exploração da temática sanitária no Brasil foi estudada por diferentes autores, que se dedicaram à análise da produção científica na saúde coletiva. Donnangelo ${ }^{30}$, em 1983, apresenta uma densa análise da produção da 'área de saúde coletiva' na década de 1970, que, ao circunscrever o campo de pesquisas, então em vias de construção, coloca uma série de questionamentos que, décadas depois, permanecem atuais. Ressalvando que pretende simplesmente ordenar parte da produção do período, classifica essa produção em duas grandes áreas: "1) produção epidemiológica, restritivamente entendida como estudos sobre saúde-doença em populações; 2) produção de estudos sobre práticas de saúde"30(30).

Essa produção epidemiológica, surgida em fins da década de 1960, buscava ultrapassar o âmbito de explicações limitado ao modelo da história natural da doença. Ao mesmo tempo, registra Donnangelo, uma vertente de estudos demográficos contribui para a incorporação de novas temáticas e metodologias, aproximando a questão demográfica das questões sanitárias. Mas seria no campo das relações entre saúde e trabalho que surgem de forma mais explícita "as linhas de recomposição das relações entre o social e as manifestações patológicas"3030(32), com a categoria 'trabalho' desempenhando um papel central nos modelos teóricos emergentes.

Quanto à produção sobre práticas de saúde, Donnangelo observa "a emergência temática da questão do planejamento e da reorganização administrativa como base para a racionalização da prática sanitária"30(32), que, nos anos 1970, assume nova inflexão, buscando evidenciar as articulações econômicas e políticas das práticas de saúde no País, incluindo estudos sobre a medicina empresarial e indústrias médicas.

Para Sonia Fleury Teixeira, em outro artigo referencial do período sobre a produção das 'ciências sociais em saúde no Brasil' ${ }^{31}$, a aproximação entre ciências sociais e medicina, iniciada nas décadas de 1950 e 1960 e aprofundada pela 'medicina social' latino-americana, não logrou conciliar os dois modelos de causalidade - natural e histórico - em um novo referencial para a epidemiologia social, capaz de dar conta da determinação social das doenças. Se, para a autora, é precisamente a incorporação das ciências sociais à medicina que constitui, de fato, a problemática do campo emergente da saúde coletiva, tal incorporação se deu a partir de "um recorte sistemático, uma incisão profunda no interior mesmo daquelas ciências, a partir da inscrição dos conteúdos disciplinares do método histórico-estrutural"31(90). A possibilidade de constituição de um campo específico de conhecimento sob o nome 'saúde coletiva' seria a adoção do 'método histórico-estrutural' - isto é, abordagens derivadas de correntes e tradições diversas do marxismo -, cuja melhor expressão, segundo Teixeira, seriam as teses mencionadas de Donnangelo e Arouca. A definição de tal problemática, apresentada como tentativa de construção de uma 'teoria social da medicina', definida por Nogueira ${ }^{32}$ sob o conceito de 'organização social da prática médica', foi um marco decisivo no campo, produzindo um deslocamento da ênfase no processo saúde-doença para o estudo das práticas de saúde, vistas sob a ótica do planejamento e da administração, mas, também, e principalmente, de suas articulações políticas, econômicas e ideológicas. 
O desenvolvimento desse novo campo, na década de 1980, já no contexto de transição para a democracia, é fortemente marcado pelo impulso reformista que culmina com a instituição de um sistema nacional e universal de saúde na Constituição Federal, promulgada em 1988. Desde o início da década, surgem importantes estudos, de corte histórico, sobre o sistema de proteção social brasileiro - e, mais especificamente, o sistema previdenciário ${ }^{33-36}$-, que apontam para a necessidade da superação daquele modelo em direção a um sistema mais includente. $O$ contexto da transição demandou das 'ciências sociais em saúde' um esforço de reflexão sobre os condicionantes do processo político e os grupos sociais capazes de dar sustentação ao projeto reformista, sob a forma de uma 'teoria da Reforma Sanitária'37. A produção do período é densa e marcada por controvérsias que refletem distintas concepções quanto à estratégia reformista em face do contexto político.

A década de 1990, por sua vez, será marcada pelas vicissitudes da implementação das diretrizes e dos princípios do SUS, consagrados na Constituição e na legislação complementar. Demarca, também, a afirmação da saúde coletiva como área de ensino e pesquisa inserida no sistema nacional de pós-graduação, sujeita às regras e aos critérios de avaliação institucionalizados. Ocorre o deslocamento em direção à 'ciência normal' de um campo até então caracterizado pelo impulso reformista, processo que será aprofundado e radicalizado na década seguinte.

Um primeiro mapeamento da produção no período foi publicado por Canesqui ${ }^{14}$, com base em um catálogo de 158 profissionais elaborado pela Abrasco, identificados, primeiramente, nas instituições da área e, em seguida, durante eventos científicos realizados no início da década de 1990. Com base em um levantamento bibliográfico não exaustivo e de áreas de interesse indicadas pelos profissionais listados no catálogo, buscou identificar a emergência de novas temáticas, que expandem significativamente o espectro de interesses que deu origem ao campo: saúde reprodutiva; sexualidade e gênero; violência; movimentos sociais; educação e comunicação em saúde; planejamento, gestão e avaliação dos 'serviços' de saúde; além de reflexões de natureza epistêmica e teórico-metodológica.

Canesqui retorna ao tema pouco depois, analisando a produção bibliográfica entre 1997 e 2007, em sete periódicos da área de saúde coletiva publicados no Brasil e disponíveis na base Scientific Electronic Library Online (SciELO), constituindo um universo de 498 $\operatorname{artigos}^{15}$. Esse estudo corrobora a tendência do surgimento de 'novas temáticas', observando, adicionalmente, o aumento dos estudos sobre 'representações sociais' e com uso de metodologias qualitativas. Mostra, igualmente, a persistência de um tema 'tradicional' da saúde coletiva - 'políticas e instituições de saúde' com cerca de um terço dos artigos analisados. Detecta, porém, uma mudança significativa de enfoque nesse segmento de investigação:

No período examinado, deparou-se com a reconstituição histórica da política de saúde, enfocando principalmente atores, grupos de interesse, condições históricas e relação com valores de nacionalidade, revertendo-se em parte o enfoque da historicidade da política, subsumida às macroestruturas econômicas e de poder, bastante dominantes nas análises anteriores ${ }^{\mathbf{1 5}(\mathbf{1 7})}$.

Ao considerar o conjunto da produção analisada, a autora conclui:

Empregaram-se as teorias de médio alcance, com abordagens compreensivas, das teorias da ação social, hermenêutica, construtivismo social, teorias da linguagem, culturais nas suas distintas versões históricas que prevaleceram sobre os enfoques macroestruturais e deterministas, que marcaram as investigações da década de 1970 até metade da década de 198015(21-22).

Além disso, a autora salienta que os enfoques disciplinares persistem e que é escassa a interlocução interdisciplinar, especialmente com as 'ciências da vida'. 
Loyola, em artigo publicado pouco antes ${ }^{\mathbf{1 0}}$, aponta esse processo de 'disciplinarização' e segmentação do campo em torno de suas 'áreas de concentração' - epidemiologia, planejamento e ciências sociais. Para a autora, o planejamento e a administração em saúde dominaram o campo até a década de 1990, passando a epidemiologia à posição preponderante no período seguinte, ao passo que as ciências sociais, embora sejam o elemento distintivo da identidade da saúde coletiva, teriam sempre ocupado uma posição subordinada. $\mathrm{O}$ desenvolvimento da pesquisa e a expansão da pós-graduação, concentrada nas universidades e instituições públicas, agravou essa situação, devido à adoção de critérios bibliométricos na avaliação da pós-graduação. O padrão de publicação da epidemiologia difere muito da pesquisa social e aproxima-se, em termos quantitativos e qualitativos, da pesquisa biomédica, resultando em grande desequilíbrio na área, em que pese a reivindicação pela saúde coletiva de um caráter interdisciplinar ${ }^{4,5}$.

O 'método histórico-estrutural' que, como assinalou Teixeira em $1985^{31}$, teria permitido a consolidação do campo nos anos 1970, daria lugar a uma maior diversidade de abordagens e perspectivas. Pode-se concluir que o novo campo não foi capaz de produzir um novo saber interdisciplinar, conciliando os modelos explicativos da biomedicina e da teoria social, como pretendido. Porém, o esforço de modernização conceitual e metodológica que caracterizou a produção original das ciências sociais em saúde na América Latina e no Brasil permanece extremamente relevante, pela capacidade de relacionar saúde e sociedade em perspectiva histórica.

\section{Ciências sociais em saúde - perspectivas contemporâneas}

O surgimento de abordagens e temáticas novas, com maior pluralidade teórica e metodológica, não reflete somente a evolução do campo de estudos sobre as relações entre saúde e sociedade; respondem a transformações sociais de longo curso e grande impacto, tanto políticas e econômicas quanto no plano da sociabilidade e das relações humanas.

As transformações ocorridas desde finais da década de 1960, quando estavam sendo elaborados alguns estudos pioneiros do que viria a constituir a 'saúde coletiva', foram muitas e complexas. Desde o final de década de 1960, o pensamento social detectou e vem buscando compreender essas transformações. Conceitos e termos como 'sociedade pós-industrial', 'sociedade da informação', 'pós-fordismo', 'pós-modernidade' (e 'pós-modernismo'), como também, não menos importante, 'globalização', vêm sendo propostos por diversos autores em diferentes momentos e lugares - geralmente, porém, em países de 'capitalismo avançado' - para descrever tais transformações ${ }^{38}$. Mais recentemente, surgem conceitos como 'sociedade de risco'39, 'modernização reflexiva'40, 'modernidade líquida' ${ }^{\mathbf{4 1}}$, visando igualmente a dar conta de aspectos hipercomplexos das sociedades contemporâneas.

Em publicação recente, Aurea Ianni17, tomando como referência as teorias da 'modernização reflexiva' 40 e 'sociedade de risco' ${ }^{39}$, de Giddens e Beck, aponta o esgotamento do arcabouço explicativo do pensamento social em saúde formulado no Brasil a partir da década de 1970, bem como das práticas e políticas da saúde pública, diante das mudanças ocorridas nas últimas décadas. A 'modernização reflexiva' evidencia as diferenças profundas entre os marcos referenciais da 'primeira modernidade' - crença no desenvolvimento econômico, científico e tecnológico - e aqueles da 'segunda modernidade', na qual processos não podem mais ser implementados sem que venham acompanhados de resultados indesejados e, muitas vezes, imperceptíveis - isto é, riscos -, que colocam o conhecimento científico diante de questionamentos permanentes.

Tal cenário de mudanças incluiria, ainda: alterações na lógica territorial das atividades 
econômicas em escala mundial; processos de integração política regional; descentralização da gestão de políticas públicas; reivindicações sociais a partir da afirmação de diferenças; e recomposições dos sistemas de proteção social, com a desagregação da sociedade salarial.

Esse contexto e a complexificação das cadeias causais dos processos saúde-doença, como apontado por Ianni, desafiam o setor saúde a mudar estratégias políticas e buscar alternativas de reorganização da ação governamental diante de cenários cada vez mais imprevisíveis.

Porém, se, como pretende Ianni, as cadeias causais se complexificaram e alguns conceitos e modelos consagrados perderam força explicativa, observa-se, na última década, um retorno às abordagens macrossociológicas apoiadas em conceitos da economia política, notadamente após a crise financeira de 2007-2008 e a recessão subsequente, com forte impacto sobre a economia global. O desmonte dos sistemas de proteção social construídos no século passado, a exaustão das políticas redistributivas perante o regime de acumulação baseado na expansão industrial e, por outro lado, o fracasso das políticas de austeridade como remédio para a crise fiscal, com efeitos devastadores sobre as economias e as finanças nacionais, trazem consigo o risco de deterioração da legitimidade dos regimes democráticos, inclusive nos países centrais ${ }^{42}$. As novas tecnologias de comunicação e da Internet, antes vistas principalmente como promessa de 'empoderamento' da sociedade civil em face dos poderes instituídos, passam também a ser vistas, hoje, como ameaça potencial à democracia ${ }^{43}$. São fenômenos que impactam diretamente a saúde e não devem ser ignorados.

Ainda no século passado, Frederic Jameson ${ }^{44}$ e David Harvey ${ }^{45}$ apontavam a convergência entre mudanças na 'lógica cultural' e transformações do capitalismo 'tardio'. Em trabalho recente, Harvey descreve um cenário de riscos ambientais e dinâmicas sociais extremamente conturbado, decorrente do imperativo de crescimento exponencial imposto pela lógica de acumulação do capital ${ }^{46}$. Processos de 'destituição' e expulsão em massa, com o surgimento de um novo mercado global de terras e expansão do agronegócio, grandes empreendimentos, acidentes industriais e catástrofes ambientais, evidenciam o caráter dramático e perturbador das dinâmicas territoriais no mundo contemporâneo e trazem desafios significativos, que a saúde pública vem enfrentando ${ }^{\mathbf{4 7}}$.

As ciências sociais vêm tentando construir instrumentos conceituais e metodológicos adequados às novas realidades emergentes no mundo social. Novos temas se apresentam, metabolizados pela reflexão especializada, que passam a integrar o repertório do discurso público sobre questões sociais, ambientais, organizacionais e sanitárias. Os próprios processos de produção do discurso público e as controvérsias que nele ocorrem devem ser estudados e reelaborados por uma ciência social efetivamente engajada em seu tempo. O pensamento social ele mesmo é parte indissociável da constituição do mundo histórico.

É esperado e necessário que novos temas de pesquisa emerjam no terreno das 'ciências sociais em saúde', no campo da saúde coletiva. Por outro lado, é fundamental reconectar a construção dos problemas de pesquisa e os grandes desafios postos às sociedades atuais, que põem as questões da interface entre saúde e sociedade em um novo patamar de complexidade e exigem do setor saúde soluções compatíveis.

\section{Ciências sociais em saúde no Brasil - desafios}

O aprofundamento da contribuição das ciências sociais à saúde coletiva é imperativo e necessário à existência futura do campo. É fundamental um convite/convocação renovado à comunidade intelectual das ciências sociais para o debate sobre os temas da saúde, da medicina e dos processos saúde-doença na contemporaneidade. Por outro lado, é desejável investir em uma maior abertura à incorporação de cientistas sociais aos quadros acadêmicos da saúde coletiva, por meio de incentivos adequados. 
*orcid (Open Researcher and Contributor ID).
As relações entre as áreas de concentração que hoje compõem o campo, em especial, entre a epidemiologia e as demais áreas, devem ser estimuladas em termos realistas de diálogo pluridisciplinar, respeitando-se as especificidades epistêmicas, teóricas e metodológicas das diferentes disciplinas e, no interior destas, suas diferentes abordagens. É crucial que os sistemas de avaliação da produção científica, particularmente na pós-graduação stricto sensu, levem em conta os distintos padrões de produção bibliográfica, de forma a viabilizar e valorizar a presença das ciências sociais nos programas de ensino e pesquisa.

A reabertura do diálogo da saúde coletiva, mediado pelas ciências sociais, com a comunidade intelectual da medicina representaria, igualmente, um grande passo adiante. Problemas como os potenciais efeitos iatrogênicos derivados do uso abusivo de tecnologias exigem análises consistentes, que poderão ser abordados adequadamente com a colaboração entre cientistas sociais e profissionais de saúde.

Outro desafio para a saúde coletiva é a atualização da política científica para o campo, à luz da compreensão possível do horizonte de

\section{Referências}

1. Vieira-da-Silva LM. O campo da saúde coletiva: gênese, transformações e articulações com a reforma sanitária. Salvador: Edufba; 2018.

2. Fundação Coordenação de Aperfeiçoamento de Pessoal de Nível Superior. Tabela de áreas de Conhecimento [acesso em 18 out 2019]. Brasília, DF: A Fundação; 2017. Disponível em: https://www.capes.gov. possibilidades para o desenvolvimento social no Brasil, nas próximas décadas. A institucionalização da produção em ciências sociais em saúde se beneficiou de uma política específica de valorização do setor de ciência e tecnologia e do planejamento governamental. As ciências sociais podem trazer uma contribuição fundamental para a construção dessa agenda.

Por fim, deve-se ressaltar o estudo das dinâmicas econômicas, políticas, sociais, culturais e, também, subjetivas, que ocorrem nas sociedades contemporâneas, e sua expressão em diferentes escalas político-territoriais. A contextualização dos processos saúde-doença em suas especificidades e singularidades é condição para a produção de respostas adequadas aos problemas novos e antigos da saúde pública brasileira, em sua configuração atual.

\section{Colaboradores}

Ribeiro PT (0000-0002-7522-5541)* e Castro L (0000-0002-9376-5103)* contribuíram igualmente na elaboração do manuscrito. br/images/documentos/documentos_diversos_2017/ TabelaAreasConhecimento_072012_atualizada_2017_ v2.pdf.

3. Fundação Coordenação de Aperfeiçoamento de Pessoal de Nível Superior. Documento de Área - Área 22: Saúde Coletiva [acesso em 18 out 2019]. Brasília, DF: A Fundação; 2019. Disponível em: https://www.capes. 
gov.br/images/Documento_de_\%C3\%Alrea_2019/ SAUDE_COLETIVA.pdf.

4. Iriart JA, Deslandes SF, Martin D, et al. A avaliação da produção científica nas subáreas da Saúde Coletiva: limites do atual modelo e contribuições para o debate. Cad. Saúde Pública. 2015; 31(10):2137-2147.

5. Costa NR. A avaliação da produção intelectual e o declínio da interdisciplinaridade na Saúde Coletiva. Physis [internet]. 2012; 22(2):681-699.

6. Kuhn T. A estrutura das revoluções científicas. São Paulo: Perspectiva; 2001.

7. Giddens A. A constituição da sociedade. São Paulo: Martins Fontes; 2003.

8. Luz MT. Complexidade do campo da Saúde Coletiva: multidisciplinaridade, interdisciplinaridade e transdisciplinaridade de saberes e práticas - análise sócio-histórica de uma trajetória paradigmática. Saúde soc. 2009; 18(2):304-311.

9. Luz MT. Especificidade da contribuição dos saberes e práticas das Ciências Sociais e Humanas para a saúde. Saúde soc. 2011 20(1):22-31.

10. Loyola MA. A saga das ciências sociais na área da Saúde Coletiva: elementos para reflexão. Physis. 2008; $18(2): 251-275$.

11. Loyola MA. O lugar das ciências sociais na saúde coletiva. Saúde soc. 2012; 21(1):9-14.

12. Minayo MCS, Assis SG, Deslandes SF, et al. Possibilidades e dificuldades nas relações entre ciências sociais e epidemiologia. Ciênc. Saúde Colet. 2003; 8(1):97-107

13. Minayo MCS. A produção de conhecimentos na interface entre as ciências sociais e humanas e a saúde coletiva. Saúde soc. 2013; 22(1): 21-31.

14. Canesqui AM. Ciências sociais e saúde no Brasil: três décadas de ensino e pesquisa. Ciênc. Saúde Colet. 1998; 3(1):131-168.
15. Canesqui AM. Produção científica das ciências sociais e humanas em saúde e alguns significados. Saúde soc. $2012 ; 21(1)$ : 15-23.

16. Nunes ED. Tendências e perspectivas das pesquisas em ciências sociais em saúde na América Latina: uma visão geral. In: Nunes ED, organizador. As ciências sociais em saúde na América Latina: tendências e perspectivas. Brasília, DF: OPAS; 1985.

17. Ianni A. Mudanças sociais contemporâneas e saúde: estudo sobre a teoria social e saúde pública no Brasil. São Paulo: Hucitec; 2018.

18. Collins R. Quatro tradições sociológicas. Petrópolis: Vozes; 2009.

19. Rosen G. The evolution of social medicine. In: Freeman HF, Levine S, Reeder, LG. Handbook of medical sociology. Englewood Cliffs, NJ: Prentice-Hall; 1963. p. 17-51.

20. Foucault M. O nascimento da medicina social. In: Microfísica do poder. 2. ed. Rio de Janeiro: Paz e Terra; 2015. p. 143-170.

21. Nunes ED. Sobre a sociologia da saúde: origens e desenvolvimento. 2. ed. São Paulo: Hucitec; 2007.

22. Nunes ED. As contribuições de Juan César Garcia às ciências sociais em saúde. In: Nunes ED, organizador. Juan César García: pensamento social em saúde na América Latina. São Paulo: Cortez; 1989. p. 11-37.

23. García JC. Juan César García entrevista Juan César García. In: Nunes ED, organizador. As ciências sociais em saúde na América Latina: tendências e perspectivas. Brasília, DF: OPAS; 1985.

24. Donnangelo MCF. Medicina e sociedade: o médico e seu mercado de trabalho. 2. ed. São Paulo: Hucitec; 2011.

25. Donnangelo MCF. Saúde e sociedade. 2. ed. São Paulo: Hucitec; 2011.

26. Arouca S. O dilema preventivista: contribuição para 
a compreensão e crítica na medicina preventiva. São Paulo: Unesp; 2003.

27. Miceli S. A Fundação Ford e os cientistas sociais no Brasil, 1962-1992. In: Miceli S, organizador. História das ciências sociais no Brasil. São Paulo: Sumaré; 1995. p. 341-396. (v. 2)

28. Miceli S. O cenário institucional das ciências sociais no Brasil. In: Miceli S, organizador. História das ciências sociais no Brasil. São Paulo: Sumaré; 1995. p. 7-24. (v. 2).

29. Ribeiro PT. A instituição do campo científico da saúde coletiva no Brasil [dissertação]. Rio de Janeiro: Escola Nacional de Saúde Pública, Fundação Oswaldo Cruz; 1991. 190 p.

30. Donnangelo MCF. A pesquisa na área de saúde coletiva no Brasil - a década de 70. In: Buss PM, organizador. Ensino de Saúde Pública, Medicina Preventiva e Social no Brasil. Rio de Janeiro: Abrasco; 1983.

31. Teixeira SMF. As ciências sociais em saúde no Brasil. In: Nunes ED, organizador. As ciências sociais em saúde na América Latina: tendências e perspectivas. Brasília, DF: OPAS; 1985

32. Nogueira RP. Medicina interna e cirurgia: a formação social da prática médica [dissertação]. Rio de Janeiro: Instituto de Medicina Social, Universidade do Estado do Rio de Janeiro; 1977.

33. Braga JCS, Paula SG. Saúde e previdência: estudos de política social. 3. ed. São Paulo: Hucitec; 2018.

34. Cohn A. Previdência social e processo político no Brasil. São Paulo: Moderna; 1980.

35. Possas C. Saúde e trabalho: a crise da previdência social. 2. ed. São Paulo: Hucitec, 1989.
36. Oliveira JAA, Teixeira SMF. (Im)previdência social: 60 anos de história da previdência no Brasil. Petrópolis: Vozes; 1985.

37. Teixeira SMF, organizadora. Reforma sanitária: em busca de uma teoria. São Paulo: Cortez; 1989.

38. Kumar K. Da sociedade pós-industrial à pós-moderna: novas teorias sobre o mundo contemporâneo. 2 . ed. Rio de Janeiro: Jorge Zahar; 2006.

39. Beck U, Sociedade de risco: rumo a uma nova modernidade. São Paulo: Ed. 34; 2010.

40. Giddens A, Lasch S, Beck U. Modernização reflexive: política, tradição e estética na ordem social moderna. 2. ed. São Paulo: Unesp; 2012.

41. Bauman Z. Modernidade líquida: Rio de Janeiro: Jorge Zahar, 2001

42. Streeck W. Tempo comprado: a crise adiada do capitalismo democrático. Coimbra: Actual; 2013.

43. Runciman. Como a democracia chega ao fim. São Paulo: Todavia, 2018

44. Jameson F. Pós-modernismo: a lógica cultural do capitalismo tardio. São Paulo: Ática, 1997.

45. Harvey D. Condição pós-moderna. São Paulo: Loyola; 1992.

46. Harvey D. 17 contradições e o fim do capitalismo. São Paulo: Boitempo; 2016.

47. Sassen S. Expulsões: brutalidade e complexidade na economia global. São Paulo: Paz e Terra; 2016.

Recebido em 24/03/2019 Aprovado em 08/12/2019

Conflito de interesses: inexistente

Suporte financeiro: não houve 